Published in final edited form as:

Dig Liver Dis. 2009 July ; 41(7): 523-533. doi:10.1016/j.dld.2008.09.011.

\title{
Human cholangiocarcinoma development is associated with dysregulation of opioidergic modulation of cholangiocyte growth $^{*}$
}



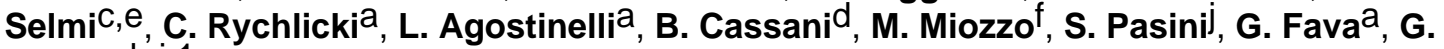
Alpinig, h,i, 1 , and A. Benedettia

aDepartment of Gastroenterology, Politechnic University of Marche, Ancona, Italy

bDepartment of Internal Medicine, Clinic Institute Humanitas IRCCS, University of Milan, Milan, Italy

cDivision of Rheumatology, Allergy and Clinical Immunology, University of California at Davis, Davis, CA, USA

dDepartment of Human Pathology, San Paolo Hospital School of Medicine, University of Milan, Milan, Italy eDivision of Internal Medicine, Department of Clinical Sciences “Luigi Sacco”, University of Milan, Milan, Italy

fMedical Genetic Unit, San Paolo Hospital School of Medicine, University of Milan, Italy

gDivision of Research, Central Texas Veterans Health Care System, Scott \& White Hospital and The Texas A \& M University System Health Science Center College of Medicine, Temple, TX, USA

$\mathrm{h}$ Department of Medicine, Scott \& White Hospital and The Texas A \& M University System Health Science Center College of Medicine, Temple, TX, USA

iDepartment of Systems Biology and Translational Medicine, Scott \& White Hospital and The Texas A \& M University System Health Science Center College of Medicine, Temple, TX, USA

jDivision of Internal Medicine and Liver Unit, San Paolo Hospital School of Medicine, University of Milan, Milan, Italy
\end{abstract}

\section{Abstract}

Background/Aims-Incidence of cholangiocarcinoma is increasing worldwide, yet remaining highly aggressive and with poor prognosis. The mechanisms that drive cholangiocyte transition towards malignant phenotype are obscure. Cholangiocyte benign proliferation is subjected to a selflimiting mechanism based on the autocrine release of endogenous opioid peptides. Despite the presence of both, ligands interact with $\delta$ opioid receptor $(\mathrm{OR})$, but not with $\mu \mathrm{OR}$, with the consequent

\footnotetext{
*This work was supported by MIUR grant 2005067975_004 to Dr. Marzioni, by MIUR grant 2006068958_001 to Dr. Benedetti, by MIUR grant 2006068958_003 to Dr. Selmi, by Università Politecnica delle Marche intramural grants ATBEN00205 to Dr. Benedetti and ATMAR01105 to Dr. Marzioni; by a VA Merit Award, a VA Research Scholar Award, the Dr. Nicholas C. Hightower Centennial Chair of Gastroenterology from Scott \& White, and the NIH grant DK062975 to Dr. Alpini.

(C) 2008 Editrice Gastroenterologica Italiana S.r.l. Published by Elsevier Ltd. All rights reserved.

*Corresponding author. Tel.: +39 0712206043; fax: +39 0712206044. E-mail address: E-mail: m.marzioni@ univpm.it (M. Marzioni).

${ }^{1}$ Dr. Nicholas C. Hightower Centennial Endowed Chair of Gastroenterology.

Conflicts of interest

None declared.
} 
inhibition of cell growth. We aimed to verify whether cholangiocarcinoma growth is associated with failure of opioidergic regulation of growth control.

Methods-We evaluated the effects of OR selective agonists on cholangiocarcinoma cell proliferation, migration and apoptosis. Intracellular signals were also characterised.

Results-Activation of $\mu \mathrm{OR}$, but not $\delta \mathrm{OR}$, increases cholangiocarcinoma cell growth. Such an effect is mediated by ERK1/2, PI3K and $\mathrm{Ca}^{2+}-$ CamKII $\alpha$ cascades, but not by cAMP/PKA and PKC $\alpha . \mu \mathrm{OR}$ activation also enhances cholangiocarcinoma cell migration and reduces death by apoptosis. The anti-apoptotic effect of $\mu \mathrm{OR}$ was PI3K dependent.

Conclusions-Our data indicate that cholangiocarcinoma growth is associated with altered opioidergic regulation of cholangiocyte biology, thus opening new scenarios for future surveillance or early diagnostic strategies for cholangiocarcinoma.

\section{Keywords}

Cholangiocarcinoma; Endogenous opioid peptides; Proliferation; Survival

\section{Introduction}

Cholangiocarcinoma is the malignancy arising from cholangiocytes, the epithelial cells lining the biliary tree [1]. Cholangiocarcinoma is a highly aggressive tumour; in particular, its incidence has been increasing worldwide over the past several decades [2] and it accounts now for $10-15 \%$ of all hepatobiliary malignancies [3].

The etiology of cholangiocarcinoma remains unclear. Several risk factors for the development of this disease, such as primary sclerosing cholangitis (PSC) or chronic hepatobiliary parasitic infections, have been identified [3]. However, it is common experience that, at least in Western countries, the majority of patients affected by cholangiocarcinoma do not show any of the known factors [3]. In addition, the majority of patients with cholangiocarcinoma have advanced and inoperable disease at the time of diagnosis and, overall, the 5-year relative survival rate after diagnosis is less than 10\% [4]. Thus, better understanding of the molecular bases of the failure of the regulation of cholangiocyte proliferation that gives rise to biliary cancer is thought to be essential for developing novel strategies and therapeutic targets to prevent, diagnose and cure this fatal neoplasm.

Normal and malignant cholangiocyte growth is regulated by neuropeptides and neuroendocrine hormones $[5,6]$. We have recently demonstrated that cholangiocytes are susceptible to the action of endogenous opioid peptides, by the activation of $\delta \mathrm{OR}$ and $\mu \mathrm{OR}$ [7]. In particular, we found that the local release of endogenous opioid peptides in the course of chronic cholestasis is functional to the activation of the $\delta \mathrm{OR}$, with the consequent inhibition of cholangiocyte hyperplastic proliferative response to injury [7].

Since endogenous opioid peptides regulate the growth of several malignancies [8-14], we wanted to verify if they also affect cholangiocarcinoma development. In particular, we aimed to answer the following questions: (i) do cholangiocarcinoma cells express $\delta \mathrm{OR}$ and $\mu \mathrm{OR}$ ? (ii) What are the effects of OR activation on cholangiocarcinoma cell proliferation? (iii) Which intracellular events do mediate the OR effects on cholangiocarcinoma cell proliferation? Is OR activation also responsible for changes in cholangiocarcinoma cell migration (iv) and death by apoptosis (v)? 


\section{Materials and methods}

\subsection{Cell culture and OR expression}

The study was performed in $\mathrm{HuH}-28, \mathrm{Mz}-\mathrm{ChA}-1$ and TFK- 1 cholangiocarcinoma cell lines $[15,16]$. Mz-ChA-1 cells, from human gallbladder [15], were a gift from Dr. G. Fitz (University of Texas Southwestern Medical Center, Dallas, TX); HuH-28, from human intrahepatic bile duct [16], and TFK-1 cells, from human extrahepatic bile duct [17], were acquired from the Cancer Cell Repository, Tohoku University, Japan. Cells were maintained in standard conditions, as previously described [18,19]. Expression of $\delta \mathrm{OR}$ (isoform 1) and $\mu \mathrm{OR}$ (isoform 1) was evaluated by immunoblots in whole cell lysate, as previously described by us and others $[7,20,21]$. OR expression was also assessed in a hepatocarcinoma cell line, Alex- 0 cells (PRF/ PLC/5), that was a gift from Prof. R. Mazzanti (University of Florence, Italy) [22].

\subsection{Effect of OR activation on cholangiocarcinoma cell proliferation}

After trypsinization, cells were seeded into 96-well plates (5000 per well) in a final volume of $100 \mu \mathrm{l}$ medium. To verify if OR activation has potential effects in inhibiting cholangiocarcinoma cell proliferation, $\mathrm{HuH}-28, \mathrm{Mz}-\mathrm{ChA}-1$ and TFK-1 were incubated in $10 \%$ FBS medium for $24 \mathrm{~h}$ at $37^{\circ} \mathrm{C}$ with (i) $0.2 \% \mathrm{BSA}$ (control) or increasing concentrations of: (ii) [D-pen2,5]-enkephalin (DPDPE, $1 \mathrm{nmol} / \mathrm{L}$ to $1 \mu \mathrm{mol} / \mathrm{L}$, $\delta$ OR selective agonist) [7,9]; (iii) $\left[\mathrm{D}-\mathrm{Ala}^{2}, \mathrm{~N}-\mathrm{Me}-\mathrm{Phe}^{4}, \mathrm{Gly}^{5}\right.$-ol]-enkephalin (DAMGO, $1 \mathrm{nmol} / \mathrm{L}$ to $1 \mu \mathrm{mol} / \mathrm{L}, \mu \mathrm{OR}$ selective agonist) [7,9]. To verify if OR activation has potential effects in stimulating cholangiocarcinoma cell proliferation, the same experimental approach was performed in cells kept in a FBS-free medium. Changes in bromodeoxyuridine (BrDU) incorporation were measured employing the Cell Proliferation ELISA BrDU assay (Roche, Monza, Italy), as previously described [7]. Changes in cell proliferation were also assayed by immunoblots for the Proliferating Cell Nuclear Antigen (PCNA) protein expression, as previously reported [7, $23,24]$.

\subsection{Characterization of OR intracellular signalling}

HuH-28 cells were incubated in FBS-free medium with (i) $0.2 \%$ BSA (control); (ii) DAMGO for 30 min. Changes in CamKII $\alpha$, PKC $\alpha$, ERK1/2 and AKT phosphorylation were then assayed by immunoblots, as previously described $[7,23]$. Changes in cAMP-dependent PKA activity was measured using the PepTag Assay Protein Kinase Kit, according to the instructions of the manufacturer, as previously described by us $[7,23]$.

HuH-28 cells were also incubated in the absence or presence of a 30 min pre-incubation with either Rp-cAMPs (100 $\mu \mathrm{mol} / \mathrm{L}$, a cAMP-dependent PKA inhibitor) [7], PD98059 (50 $\mu \mathrm{mol} /$ L, a MEK inhibitor) [7,25], wortmannin (100 nmol/L, a PI3K inhibitor) [7], BAPTA/AM (an intracellular $\mathrm{Ca}^{2+}$ chelator, $5 \mu \mathrm{mol} / \mathrm{L}$ ) [7,23], KN62 [10 $\mu \mathrm{mol} / \mathrm{L}$, a Calcium-Calmoduline-

Kinase (CamK) II inhibitor] [7], or Ro-32-0432 (0.5 $\mu \mathrm{mol} / \mathrm{L}, \mathrm{a} \mathrm{Ca}^{2+}$-dependent PKC inhibitor) [7]. Changes in cell proliferation were then assayed as described above.

\subsection{Effect of $O R$ activation on cholangiocarcinoma cell migration}

Changes in cholangiocarcinoma cell migration were assessed by "wound-healing" assay, as we previously described [18], and by the CytoSelect ${ }^{\mathrm{TM}} 24-$ well cell migration assay. Briefly, 30,000 cells/well, after starvation overnight, were seeded in serum-free CMRL1066 and placed in the upper well insert of a 24-well plate, in absence or presence of DAMGO $(100 \mathrm{nmol} / \mathrm{L})$, and allowed to migrate toward FBS as chemoattractant to the lower well. After 24-h incubation, cells that migrated through the $8 \mu \mathrm{m}$ pore membranes, located at the bottom of every well insert, were first dissociated from membrane, then lysed and detected by patented 
CyQuantGRDye (Invitrogen, Milan, Italy) in a fluorescence plate reader at $480 \mathrm{~nm} / 520 \mathrm{~nm}$ wavelength.

\subsection{Effect of OR activation on cholangiocarcinoma cell survival}

After trypsinization, 5000 cells/well were seeded into 96-well plates in a final volume of 50 $\mu 1$ medium. Cell death by apoptosis was induced by incubating HuH-28 in FBS-free medium for $4 \mathrm{~h}$ with glycochenodeoxycholic acid (GCDCA, $400 \mathrm{nmol} / \mathrm{L}$ ) [26,27], in the absence or presence of a 30 min pre-incubation with DAMGO.

To define the intracellular pathways that mediate the effect of DAMGO on cholangiocarcinoma cell survival, the above experiments were also performed in the absence or presence of a 30 min pre-incubation with either, PD98059 $(50 \mu \mathrm{mol} / \mathrm{L})[7,25]$, wortmannin $(100 \mathrm{nmol} / \mathrm{L})$ [7] or KN62 [10 $\mu \mathrm{mol} / \mathrm{L}$, a CamKII inhibitor] [7].

Changes in caspase 3 activation were then measured by the APO-ONE Homogeneous Caspase-3/7, according to the instruction provided by the vendor.

\subsection{Materials}

Reagents were purchased from Sigma-Aldrich (Milan, Italy) unless otherwise indicated. PD98059, Rp-cAMPs, KN62, Ro-32-0432, BAPTA/AM were purchased from Calbiochem (Milan, Italy). All the antibodies employed for immunoblotting studies were purchased from Santa Cruz (Milan, Italy), for the exception of the one for $\beta$-actin (Sigma-Aldrich, Milan, Italy). PepTag Assay Protein Kinase A Kit and APO-ONE Homogeneous Caspase-3/7 Assay were purchased from Promega (Milan, Italy). CytoSelect ${ }^{\mathrm{TM}} 24$-well cell migration assay was purchased from Cellbiolabs (Heidelberg, Germany).

\subsection{Statistical analysis}

All data are expressed as mean \pm S.E. and expressed as $\%$ of basal value, unless differently indicated. Differences between groups were analyzed by student's $t$-test if two groups were analyzed or analysis of variance (ANOVA) if more than two groups were considered.

\section{Results}

\section{1. $\mu O R$, but not $\delta O R$, activation affects cholangiocarcinoma cell proliferation, increasing growth}

Similarly to what observed in normal and hyperplastic cholangiocytes [7], malignant cholangiocytes express both $\delta \mathrm{OR}$ and $\mu \mathrm{OR}$ (Fig. 1). In contrast, no expression neither of $\delta$ ORnor of $\mu$ OR was found in hepatocarcinoma cells (Alex-0 cells, Fig. 1).

Incubation of both HuH-28, Mz-ChA-1 and TFK-1 cells with DPDPE or DAMGO did not modify cell proliferation when experiments were performed in 10\% FBS medium (not shown). In contrast, when cells were kept in FBS-free medium, increasing doses of DAMGO enhanced cell proliferation in a dose-dependent fashion; no effects were instead elicited by DPDPE (Fig. $2 \mathrm{~A}-\mathrm{C})$.

Increasing concentrations of DPDPE did not induce any change in PCNA protein expression in $\mathrm{HuH}-28$ cells (Fig. 2D), thus confirming that activation of $\delta \mathrm{OR}$ does not affect cholangiocarcinoma cell proliferation. 


\section{2. $\mu \mathrm{OR}$ signal in cholangiocarcinoma cells is mediated by ERK1/2, $\mathrm{PI} 3 \mathrm{~K}$ and $\mathrm{Ca}^{2+}$ CamKIla pathways}

Incubation of HuH-28 cells with increasing concentrations of DAMGO dose-dependently increased ERK1/2 and AKT phosphorylation (Fig. 3A), whereas no changes in PKA activity were detectable in the same conditions (Fig. 3B).

When the $\mathrm{Ca}^{2+}$ signalling was studied, we found that DAMGO dose-dependently stimulated CamKII $\alpha$ phosphorrylation (Fig. 3C, left), whereas no changes were observed in $\mathrm{PKC} \alpha$ phosphorylation (Fig. 3C, right).

As a confirmation, the increase in HuH-28 cell proliferation induced by DAMGO was neutralized by the pre-incubation with the MEK, PI3K and CamKII inhibitors or by the intracellular $\mathrm{Ca}^{2+}$ chelator, but not by the pre-incubation with the PKA or $\mathrm{Ca}^{2+}$-dependent PKC inhibitors (Fig. 4A).

DAMGO-induced increase in ERK1/2 phosphorylation was neutralized by the pre-incubation with MEK inhibitor or with PI3K inhibitor, but not by the pre-incubation with PKA, CamKII or $\mathrm{Ca}^{2+}$-dependent $\mathrm{PKC}$ inhibitors or with the intracellular $\mathrm{Ca}^{2+}$ chelator (Fig. 4B). In contrast, DAMGO-induced increase in AKT phosphorylation was only prevented by the PI3K inhibitor and not by any of the other inhibitors we tested (Fig. 4C).

\section{3. $\mu O R$ activation enhances cholangiocarcinoma cell migration}

The presence of DAMGO enhanced cell migration, that resulted in increased rapidity in wound closure: area included within the wound margins was found smaller both at 24 and at $72 \mathrm{~h}$ when cells were incubated with DAMGO than in control (Fig. 5A). Similarly, DAMGO increased migration rate when it was assessed by the specific cell migration assay (Fig. 5B).

\section{4. $\mu O R$ activation enhances cholangiocarcinoma cell survival in a PI3K-dependent manner}

Exposure of HuH-28 cells to GCDCA resulted in a marked increase in caspase 3 activity compared to control. When cells were pre-incubated with DAMGO, GCDCA-induced increase in caspase 3 activity was significantly diminished (Fig. 6A). Such an effect was mediated by the PI3K pathway, since the pre-incubation with wortmannin neutralised the DAMGO effects on GCDCA-induced increase in caspase 3 activity (Fig. 6B). The blockage of the MAPK or CamKII pathways (by PD98059 and KN62, respectively) did not affect the ability of DAMGO to inhibit the GCDCA-induced increase in caspase 3 activity (Fig. 6B).

\section{Discussion}

The current study demonstrates that malignant cholangiocytes lose the response to the inhibition of cell growth by endogenous opioid peptides, that is, in contrast, typical of hyperplastic cholangiocytes [7]. Rather, our data indicate that human cholangiocarcinoma cells respond with increased growth to the effect of endogenous opioid peptides. In particular, this study shows that: (i) human cholangiocarcinoma cells express both $\delta \mathrm{OR}$ and $\mu \mathrm{OR}$; (ii) human cholangiocarcinoma cell growth cannot be inhibited by OR activation; $\mu \mathrm{OR}$, but not $\delta \mathrm{OR}$, activation results in significant increase in cholangiocarcinoma cell proliferation; (iii) $\mu \mathrm{OR}$ signal is mediated by ERK1/2, PI3K and $\mathrm{Ca}^{2+} / \mathrm{CamKII} \alpha$ pathways; (iv) $\mu \mathrm{OR}$ enhances cholangiocarcinoma cell migration and escape from apoptosis.

Cholangiocarcinoma represents a challenge for clinicians, with most patients having an advanced disease at the time of diagnosis [4]. 
As for other malignancies, studies of the last 5-10 years demonstrated that what gives rise to cholangiocarcinoma is the failure of the mechanisms that overviewcell proliferation, survival and invasiveness [3]. What makes these mechanisms to fail remains an enigma.

Malignant transformation of cholangiocytes occurs in an environment characterized by chronic inflammation and cholestasis [3]. Such a biological milieu is associated with increased production of cytokines and molecules, like IL-6, hepatic growth factor (HGF), cyclooxygenase (COX)-2, epidermal growth factor (EGF), that have been demonstrated to be directly or indirectly responsible for promoting cholangiocarcinoma development [28-32].

Asecond major feature of chronic cholestasis is the release of a number of neuropeptides by cholangiocytes; it is now thought that such a property of cholangiocytes allows them to establish cell-to-cell interactions and most importantly to modulate their adaptive response to cholestasis itself [6]. It is not known, however, if the failure of those mechanisms is associated in any way to cholangiocarcinoma development.

It has been demonstrated that both human and experimental cholestasis is associated to the synthesis by liver cells of endogenous opioid peptides [33-36]. Recently, it has been shown that the biliary epithelium express OR [7,37], the activation of which aims to limit the cholangiocyte hyperplastic proliferative response to cholestasis [7]. Endogenous opioid peptides also play a significant role in the modulation of cancer cell growth, in particular of gastrointestinal malignancies [8-10].

In the current study, we thus wanted to verify if cholangiocarcinoma development is associated to the dysregulation of endogenous opioid peptides modulation of biliary cell growth.

In rodent non-malignant cholangiocytes, $\delta \mathrm{OR}$ and $\mu \mathrm{OR}$ activation results in opposite effects: when $\delta \mathrm{OR}$ is stimulated, a marked inhibition of cholangiocyte proliferation is observed [7]. In contrast, exposure to the $\mu \mathrm{OR}$ agonist only slightly increases cell growth [7]. In addition, in in vivo models we demonstrated that the $\delta \mathrm{OR}$ inhibitory effect is the one that largely prevails in pathophysiologic conditions [7]. Such effects are not species-specific, since OR activation exerts similar effects on cell growth also when their activation is elicited in a human cholangiocyte cell line (Marzioni et al., 2008, unpublished observations). In malignant cholangiocytes $\delta \mathrm{OR}$ activation has no effects on cell growth, whereas $\mu \mathrm{OR}$ activation resulted in a significant increase in cell proliferation (Fig. 2). These data indicate that malignant cholangiocytes differ from hyperplastic (e.g. non-malignant) ones [7]: they lose the susceptibility to the effect of the growth-inhibitor OR (e.g. $\delta$ OR). Rather, and still in contrast with non-malignant cholangiocytes [7], they display a marked response to growth-stimulator OR (e.g. $\mu \mathrm{OR}$ ). Altogether, our findings suggest the concept that, similarly to what happens in other cells $[38,39]$, the malignant transformation of cholangiocytes is associated with the loss of their response to anti-proliferative factors and with the maintenance/amplification of the response to pro-proliferative stimuli. If no expression of OR was found in hepatocarcinoma cells (Fig. 1), the dysregulation of opioidergic modulation of cholangiocyte growth was evident in all the three cell lines tested (Fig. 2). Therefore, these data indicate that: (i) locally released endogenous opioid peptides are significant for biliary cancerogenesis independently from the origin of the neoplasm along the biliary tract, since the same effects were evoked in cholangiocarcinoma cells originated from intra- and extra-hepatic ducts and from gallbladder [15-17]. To this regard, endogenous opioid peptides behaved similarly to other neuropeptides $[18,19,40,41]$. (ii) The role of locally released endogenous opioid peptides is substantially specific for biliary cancerogenesis, since hepatocarcinoma cells, as much as non-malignant rodent and human hepatocytes [7], do not express OR.

We also found that the intracellular signalling is completely dysregulated in malignant cholangiocytes when compared to hyperplastic ones [7]. In the latter, upon $\delta$ OR stimulation, 
the activation of the $\mathrm{Ca}^{2+}$ signalling $\left(\mathrm{Ca}^{2+} / \mathrm{CamKII} \alpha / \mathrm{PKC} \alpha\right)$ results in a potent inhibition of the PI3K/ERK1/2 cascade, with the consequent inhibition of cell growth [7]. In addition, $\mu \mathrm{OR}$ stimulates cell growth through the PI3K/ERK1/2 cascade, but without affecting the $\mathrm{Ca}^{2+}$ signalling at all [7]. In contrast, in malignant cholangiocytes we found that $\mu \mathrm{OR}$ activates $\mathrm{Ca}^{2+} / \mathrm{CamKII} \alpha$ cascade that elicits, instead of inhibiting, cell growth (Fig. 3B and A). These data are in accordance with what previously observed in cholangiocarcinoma and other malignancies: elevated levels of $\mathrm{Ca}^{2+}{ }_{-}$bound CamK are associated with cancer promotion, invasiveness and immortalization [42-44]. These data, therefore, raise the interesting hypothesis that the failure of the mechanisms that limit cholangiocyte proliferative response to cholestasis (and the consequent development of biliary malignancies) may be ascribed to the dysregulation of $\mathrm{Ca}^{2+} / \mathrm{CamK}$ signalling. The transition towards malignancy is also associated to the complete loss of any role played by the cAMP/PKA pathway, that is a major mediator of extracellular stimuli in non-malignant cholangiocytes [6]. It is needed to mention that such changes in intracellular signals could be eventually ascribed to species-specific differences between rodent hyperplastic cholangiocytes and human cholangiocarcinoma cells. Despite that such an hypothesis cannot be completely ruled out, it is more likely that those changes are due to the different biological state (hyperplastic vs. malignant): as mentioned above, rodent and human cholangiocytes do not show any differences in terms of OR expression [7] and biological response to OR activation.

In addition to uncontrolled cell proliferation, escape from apoptosis and enhanced invasiveness are the other two major biological features of cholangiocarcinoma, that equally contribute to its malignancy [3]. In this study we found that the exposure to the selective $\mu$ OR agonist accelerated HuH-28 cell migration, as resulted by both the wound-healing experiments and a specific assay (Fig. 5A and B). Similarly, incubation with $\mu \mathrm{OR}$ agonist tended to reduce the bile acid-induced activation of caspase 3 (Fig. 6A). Such an effect was mediated by the PI3K pathway, since the pre-incubation with wortmannin neutralized the anti-apoptotic effect of DAMGO (Fig. 6B). Our findings are thus in accordance with previous studies that showed PI3K to be a major factor for cholangiocarcinoma cell survival [32,45-48]. To this extent, it is accepted that cholangiocarcinoma does not differ from hepatocarcinoma [49-51] and other malignancies [52].

Altogether, our findings are in agreement with the concept that changes in cholangiocarcinoma cell proliferation are associated with parallel modifications of cell migration and opposite tendency to cell death by apoptosis [18].

In conclusion, our study demonstrates for the first time that opioidergic modulation of cholangiocyte biology is dysregulated in human cholangiocarcinoma cells, with a consequent promotion of growth, survival and migration. This study thus confirm the hypotheses that had been previously made by us and others [37,53]. Further studies are needed to clarify the actual role of endogenous opioid peptides in human cases of cholangiocarcinogenesis. It can be conceived that a genetic or acquired disruption of opioidergic regulation of cholangiocyte biology may confer to a subset of patients a higher risk of developing such a malignancy. As such and in perspective, the findings of the current study may thus open new scenarios for novel surveillance or early diagnosis strategies for cholangiocarcinoma in the near future.

\section{Practice points}

- Malignant cholangiocytes are insensitive to the growth inhibition effect of $\delta \mathrm{OR}$ activation.

- Malignant cholangiocytes only respond to the activation of $\mu \mathrm{OR}$, that promotes growth, survival and migration. 
Such a dysregulation of OR regulation of cholangiocyte biology may be relevant for cholangiocarcinoma development.

\section{Research agenda}

- To verify if a genetic or acquired disruption of opioidergic regulation of cholangiocyte biology may confer to a subset of patients a higher risk of developing cholangiocarcinoma.

- To verify if this information may contribute to develop novel strategies for surveillance or early diagnosis of cholangiocarcinoma.

\section{List of Abbreviations}

cAMP, cyclic adenosine 3',5'-monophosphate; PKA, protein kinase A; ERK, extracellular regulated kinases; PI3K, phosphatidyl-inositol-3-kinase; OR, opioid receptor; BrDU, bromodeoxyuridine; GCDCA, glycochenodeoxycholic acid.

\section{References}

1. Ahrendt SA, Nakeeb A, Pitt HA. Cholangiocarcinoma. Clin Liver Dis 2001;5:191-218. [PubMed: 11218916]

2. Patel T. Worldwide trends in mortality from biliary tract malignancies. BMC Cancer 2002;2:10. [PubMed: 11991810]

3. Lazaridis KN, Gores GJ. Cholangiocarcinoma. Gastroenterology 2005;128:1655-1667. [PubMed: 15887157]

4. Vauthey JN, Blumgart LH. Recent advances in the management of cholangiocarcinomas. Semin Liver Dis 1994;14:109-114. [PubMed: 8047893]

5. Fava G, Marzioni M, Benedetti A, Glaser S, DeMorrow S, Francis H, et al. Molecular pathology of biliary tract cancers. Cancer Lett 2007;250:155-167. [PubMed: 17069969]

6. Alvaro D, Mancino MG, Glaser S, Gaudio E, Marzioni M, Francis H, et al. Proliferating cholangiocytes: a neuroendocrine compartment in the diseased liver. Gastroenterology 2007;132:415-431. [PubMed: 17241889]

7. Marzioni M, Alpini G, Saccomanno S, de Minicis S, Glaser S, Francis H, et al. Endogenous opioids modulate the growth of the biliary tree in the course of cholestasis. Gastroenterology 2006;130:18311847. [PubMed: 16697745]

8. Zagon IS, Hytrek SD, McLaughlin PJ. Opioid growth factor tonically inhibits human colon cancer cell proliferation in tissue culture. Am J Physiol 1996;271:R511-R518. [PubMed: 8853370]

9. Zagon IS, Smith JP, McLaughlin PJ. Human pancreatic cancer cell proliferation in tissue culture is tonically inhibited by opioid growth factor. Int J Oncol 1999;14:577-584. [PubMed: 10024694]

10. Zagon IS, Wu Y, McLaughlin PJ. Opioid growth factor is present in human and mouse gastrointestinal tract and inhibits DNA synthesis. Am J Physiol 1997;272:R1094-R1104. [PubMed: 9140007]

11. Panagiotou S, Hatzoglou A, Calvo F, Martin PM, Castanasc E. Modulation of the estrogen-regulated proteins cathepsin D and pS2 by opioid agonists in hormone-sensitive breast cancer cell lines (MCF7 and T47D): evidence for an interaction between the two systems. J Cell Biochem 1998;71:416-428. [PubMed: 9831078]

12. Panagiotou S, Bakogeorgou E, Papakonstanti E, Hatzoglou A, Wallet F, Dussert C, et al. Opioid agonists modify breast cancer cell proliferation by blocking cells to the G2/M phase of the cycle: involvement of cytoskeletal elements. J Cell Biochem 1999;73:204-211. [PubMed: 10227383]

13. Bisignani GJ, McLaughlin PJ, Ordille SD, Beltz MS, Jarowenko MV, Zagon IS. Human renal cell cancer proliferation in tissue culture is tonically inhibited by opioid growth factor. J Urol 1999;162:2186-2191. [PubMed: 10569617] 
14. McLaughlin PJ, Levin RJ, Zagon IS. Regulation of human head and neck squamous cell carcinoma growth in tissue culture by opioid growth factor. Int J Oncol 1999;14:991-998. [PubMed: 10200353]

15. Knuth A, Gabbert H, Dippold W, Klein O, Sachsse W, Bitter-Suermann D, et al. Biliary adenocarcinoma. Characterisation of three new human tumor cell lines. J Hepatol 1985;1:579-596. [PubMed: 4056357]

16. Kusaka Y, Muraoka A, Tokiwa T, Sato J. Establishment and characterization of a human cholangiocellular carcinoma cell line. Hum Cell 1988;1:92-94. [PubMed: 2856443]

17. Saijyo S, Kudo T, Suzuki M, Katayose Y, Shinoda M, Muto T, et al. Establishment of a newextrahepatic bile duct carcinoma cell line, TFK-1. Tohoku J Exp Med 1995; 177:61-71. [PubMed: 8693487]

18. Fava G, Marucci L, Glaser S, Francis H, De Morrow S, Benedetti A, et al. gamma-Aminobutyric acid inhibits cholangiocarcinoma growth by cyclic AMP-dependent regulation of the protein kinase A/ extracellular signal-regulated kinase 1/2 pathway. Cancer Res 2005;65:11437-11446. [PubMed: 16357152]

19. Kanno N, Glaser S, Chowdhury U, Phinizy JL, Baiocchi L, Francis H, et al. Gastrin inhibits cholangiocarcinoma growth through increased apoptosis by activation of $\mathrm{Ca}^{2+}$-dependent protein kinase C-alpha. J Hepatol 2001;34:284-291. [PubMed: 11281558]

20. Bao L, Jin SX, Zhang C, Wang LH, Xu ZZ, Zhang FX, et al. Activation of delta opioid receptors induces receptor insertion and neuropeptide secretion. Neuron 2003;37:121-133. [PubMed: 12526778]

21. Zhang N, Rogers TJ, Caterina M, Oppenheim JJ. Proinflammatory chemokines, such as C-C chemokine ligand 3, desensitize mu-opioid receptors on dorsal root ganglia neurons. J Immunol 2004;173:594-599. [PubMed: 15210821]

22. Sterpetti P, Marucci L, Candelaresi C, Toksoz D, Alpini G, Alpini G, Ugili L, et al. Cell proliferation and drug resistance in hepatocellular carcinoma are modulated by Rho GTPase signals. Am J Physiol Gastrointest Liver Physiol 2006;290:G624-G632. [PubMed: 16322093]

23. Marzioni M, Glaser S, Francis H, Marucci L, Benedetti A, Alvaro D, et al. Autocrine/paracrine regulation of the growth of the biliary tree by the neuroendocrine hormone serotonin. Gastroenterology 2005;128:121-137. [PubMed: 15633129]

24. Mancino A, Mancino MG, Glaser S, Alpini G, Bolognese A, Izzo L, et al. Estrogens stimulate the proliferation of human cholangiocarcinoma by inducing the expression and secretion of vascular endothelial growth factor. Dig Liver Dis. 2008

25. Qiao L, Yacoub A, Studer E, Gupta S, Pei XY, Grant S, et al. Inhibition of the MAPK and PI3K pathways enhances UDCA-induced apoptosis in primary rodent hepatocytes. Hepatology 2002;35:779-789. [PubMed: 11915023]

26. Bucher BT, Feng X, Jeyabalan G, Zhang B, Shao L, Guo Z, et al. Glycochenodeoxycholate (GCDC) inhibits cytokine induced iNOS expression in rat hepatocytes. J Surg Res 2007;138:15-21. [PubMed: 17174337]

27. Higuchi H, Yoon JH, Grambihler A, Werneburg N, Bronk SF, Gores GJ. Bile acids stimulate cFLIP phosphorylation enhancing TRAIL-mediated apoptosis. J Biol Chem 2003;278:454-461. [PubMed: 12407100]

28. Matsumoto K, Fujii H, Michalopoulos G, Fung JJ, Demetris AJ. Human biliary epithelial cells secrete and respond to cytokines and hepatocyte growth factors in vitro: interleukin-6, hepatocyte growth factor and epidermal growth factor promote DNA synthesis in vitro. Hepatology 1994;20:376-382. [PubMed: 8045498]

29. Park J, Tadlock L, Gores GJ, Patel T. Inhibition of interleukin 6-mediated mitogen-activated protein kinase activation attenuates growth of a cholangiocarcinoma cell line. Hepatology 1999;30:11281133. [PubMed: 10534331]

30. Endo K, Yoon BI, Pairojkul C, Demetris AJ, Sirica AE. ERBB-2 overexpression and cyclooxygenase-2 up-regulation in human cholangiocarcinoma and risk conditions. Hepatology 2002;36:439-450. [PubMed: 12143054]

31. Sirica AE, Lai GH, Endo K, Zhang Z, Yoon BI. Cyclooxygenase-2 and ERBB-2 in cholangiocarcinoma: potential therapeutic targets. Semin Liver Dis 2002;22:303-313. [PubMed: 12360423] 
32. Zhang Z, Lai GH, Sirica AE. Celecoxib-induced apoptosis in rat cholangiocarcinoma cells mediated by Akt inactivation and Bax translocation. Hepatology 2004;39:1028-1037. [PubMed: 15057907]

33. Bergasa NV, Liau S, Homel P, Ghali V. Hepatic Met-enkephalin immunoreactivity is enhanced in primary biliary cirrhosis. Liver 2002;22:107-113. [PubMed: 12028403]

34. Bergasa NV, Sabol SL, Young WS 3rd, Kleiner DE, Jones EA. Cholestasis is associated with preproenkephalin mRNA expression in the adult rat liver. Am J Physiol 1995;268:G346-G354. [PubMed: 7864131]

35. Bergasa NV, Vergalla J, Swain MG, Jones EA. Hepatic concentrations of proenkephalin-derived opioids are increased in a rat model of cholestasis. Liver 1996;16:298-302. [PubMed: 8938629]

36. Swain MG, Rothman RB, Xu H, Vergalla J, Bergasa NV, Jones EA. Endogenous opioids accumulate in plasma in a rat model of acute cholestasis. Gastroenterology 1992;103:630-635. [PubMed: 1634078]

37. Nicoll J, Axiotis CA, Bergasa NV. The delta opioid receptor 1 is expressed by proliferating bile ductules in rats with cholestasis: implications for the study of liver regeneration and malignant transformation of biliary epithelium. Med Hypotheses 2005;65:1099-1105. [PubMed: 16125331]

38. Baniahmad A. Nuclear hormone receptor co-repressors. J Steroid Biochem Mol Biol 2005;93:89-97. [PubMed: 15860250]

39. Robertson GP. Functional and therapeutic significance of Akt deregulation in malignant melanoma. Cancer Metastasis Rev 2005;24:273-285. [PubMed: 15986137]

40. DeMorrow S, Glaser S, Francis H, Venter J, Vaculin B, Vaculin S, et al. Opposing actions of endocannabinoids on cholangiocarcinoma growth: recruitment of Fas and Fas ligand to lipid rafts. J Biol Chem 2007;282:13098-13113. [PubMed: 17329257]

41. Alvaro D, Barbaro B, Franchitto A, Onori P, Glaser S, Alpini G, et al. Estrogens and insulin-like growth factor 1 modulate neoplastic cell growth in human cholangiocarcinoma. Am J Pathol 2006;169:877-888. [PubMed: 16936263]

42. Hait WN, Lazo JS. Calmodulin: a potential target for cancer chemotherapeutic agents. J Clin Oncol 1986;4:994-1012. [PubMed: 2423656]

43. Ito $\mathrm{H}$, Wang JZ, Shimura K. Inhibition of lung metastasis by a calmodulin antagonist, $\mathrm{N}$-(6aminohexyl)-5-chloro-1-naphthalenesulfonamide (W-7), in mice bearing Lewis lung carcinoma. Anticancer Res 1991;11:249-252. [PubMed: 2018358]

44. Ahn EY, Pan G, Oh JH, Tytler EM, McDonald JM. The combination of calmodulin antagonists and interferon-gamma induces apoptosis through caspase-dependent and -independent pathways in cholangiocarcinoma cells. Am J Pathol 2003;163:2053-2063. [PubMed: 14578204]

45. Chen Y, Xu J, Jhala N, Pawar P, Zhu ZB, Ma L, et al. Fas-mediated apoptosis in cholangiocarcinoma cells is enhanced by 3,3'-diindolylmethane through inhibition ofAKTsignaling and FLICE-like inhibitory protein. Am J Pathol 2006;169:1833-1842. [PubMed: 17071604]

46. Kobayashi S, Werneburg NW, Bronk SF, Kaufmann SH, Gores GJ. Interleukin-6 contributes to Mcl-1 up-regulation and TRAIL resistance via an Akt-signaling pathway in cholangiocarcinoma cells. Gastroenterology 2005;128:2054-2065. [PubMed: 15940637]

47. Chiorean MV, Guicciardi ME, Yoon JH, Bronk SF, Kaufmanns SH, Gores GJ. Imatinib mesylate induces apoptosis in human cholangiocarcinoma cells. Liver Int 2004;24:687-695. [PubMed: 15566522]

48. Wu T, Leng J, Han C, Demetris AJ. The cyclooxygenase-2 inhibitor celecoxib blocks phosphorylation of Akt and induces apoptosis in human cholangiocarcinoma cells. Mol Cancer Ther 2004;3:299-307. [PubMed: 15026550]

49. Lin SJ, Chang C, Ng AK, Wang SH, Li JJ, Hu CP. Prevention of TGF-beta-induced apoptosis by interlukin-4 through Akt activation and p70S6K survival signaling pathways. Apoptosis 2007;12:1659-1670. [PubMed: 17624592]

50. Shen J, Jiang J, Wei Y, Zhou L, Liu D, Zhou J, et al. Two specific inhibitors of the phosphatidylinositol 3-kinase LY294002 and wortmannin up-regulate beta1,4-galactosyltransferase I and thus sensitize SMMC-7721 human hepatocarcinoma cells to cycloheximide-induced apoptosis. Mol Cell Biochem 2007;304:361-367. [PubMed: 17557191]

51. Thorgeirsson SS, Teramoto T, Factor VM. Dysregulation of apoptosis in hepatocellular carcinoma. Semin Liver Dis 1998;18:115-122. [PubMed: 9606809] 
52. New DC, Wu K, Kwok AW, Wong YH. G protein-coupled receptor-induced Akt activity in cellular proliferation and apoptosis. FEBS J 2007;274:6025-6036. [PubMed: 17949438]

53. Marzioni M, Svegliati Baroni G, Alpini G, Benedetti A. Endogenous opioid peptides and chronic liver disease: from bedside to bench. J Hepatol 2007;46:583-586. [PubMed: 17313989] 


\section{$\delta \mathrm{OR}$}

- -

$-50 \mathrm{kD}$

$\mu \mathrm{OR}$

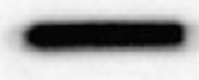

$\longrightarrow$

$-46 \mathrm{kD}$

$\beta$-actin

Comenom

$\longrightarrow$

$\longrightarrow$

ens

$-42 \mathrm{kD}$
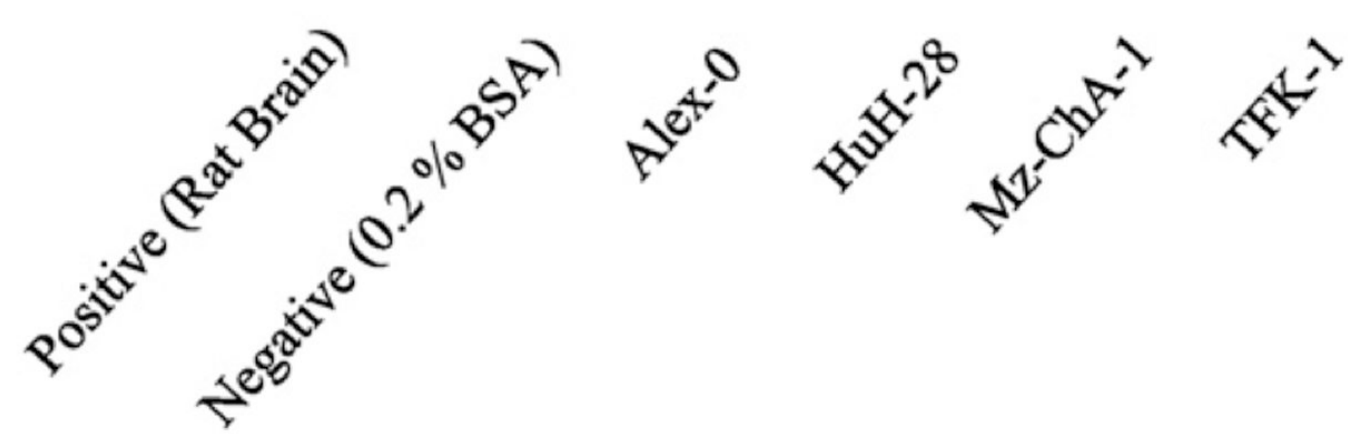

Fig. 1.

Evaluation of OR expression in cells of three different cholangiocarcinoma cell lines (MzChA-1, TFK-1 and HuH-28) and in a hepatocarcinoma cell line (Alex- 0 cells), assessed by immunoblotting. The cells of the three cholangiocarcinoma cell lines express both $\delta \mathrm{OR}$ and $\mu \mathrm{OR}$, whereas no expression was found in hepatocarcinoma cells. 
(A) HuH-28 cells

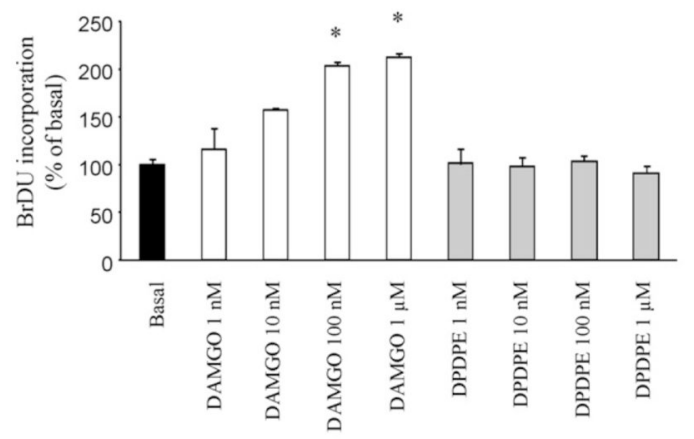

(B) Mz-ChA-1 cells

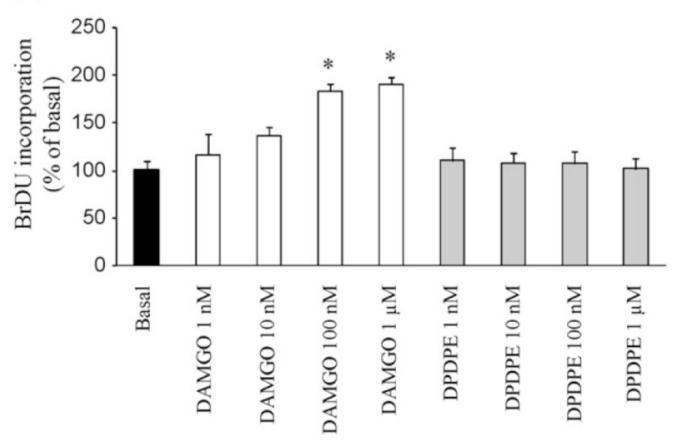

(C) TFK-1 cells

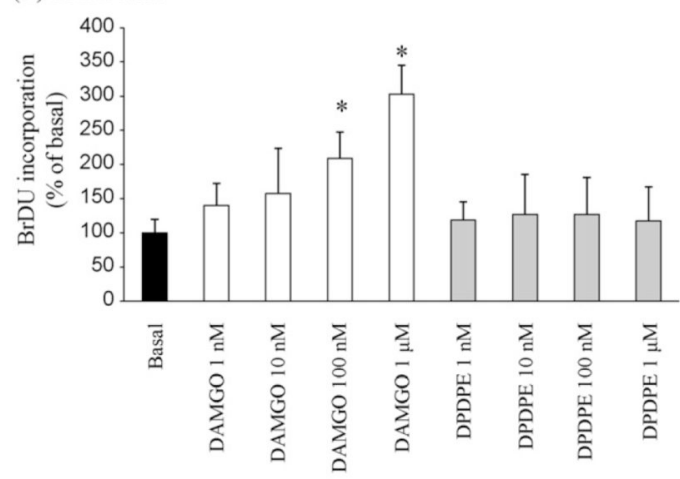

(D)
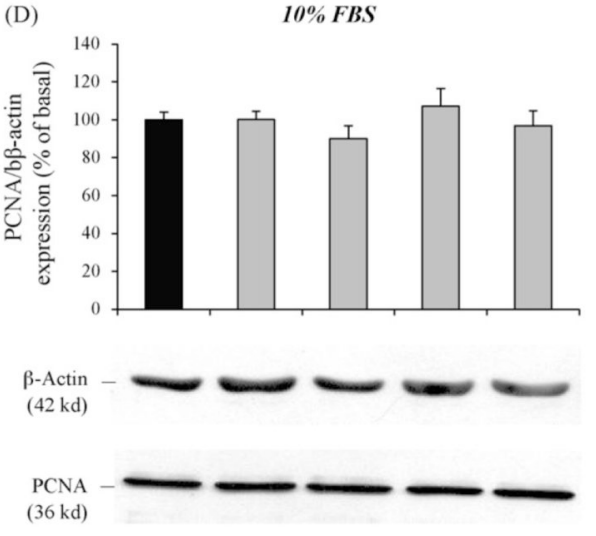

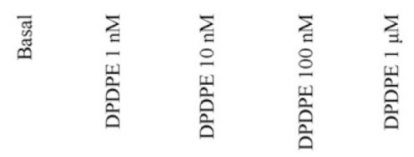

FBS-free

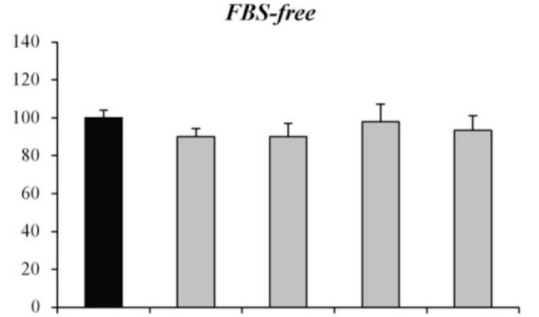

$$
\begin{array}{r}
\beta \text {-Actin } \\
(42 \mathrm{kd})
\end{array}
$$
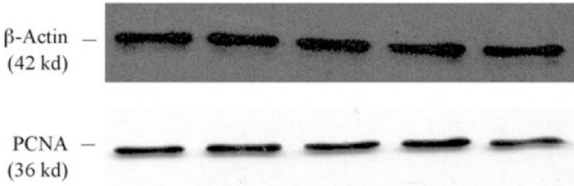

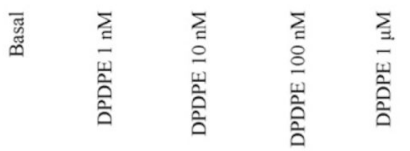

Fig. 2.

Effect of OR activation on human cholangiocarcinoma cell proliferation cultured in FBS-free medium, measured by BrDU incorporation (A-C). Increasing doses of $\mu \mathrm{OR}$ (DAMGO), but not of $\delta$ OR (DPDPE), selective agonist markedly increased HuH-28 (A), Mz-ChA-1 (B) and TFK-1 (C) cholangiocarcinoma cell proliferation. Data are expressed as mean \pm S.E. of three experiments. ${ }^{*} p<0.05$ vs. basal. (D) Effect of $\delta \mathrm{OR}$ activation on $\mathrm{HuH}-28$ cell proliferation assessed by PCNA protein expression. Increasing concentrations of DPDPE did not determine changes in PCNA protein expression, neither in cells cultured in the presence (left) nor in the absence (right) of $10 \%$ FBS-enriched medium. Data are expressed as mean \pm S.E. of three experiments. ${ }^{*} p \leq 0.05$ vs. basal. 

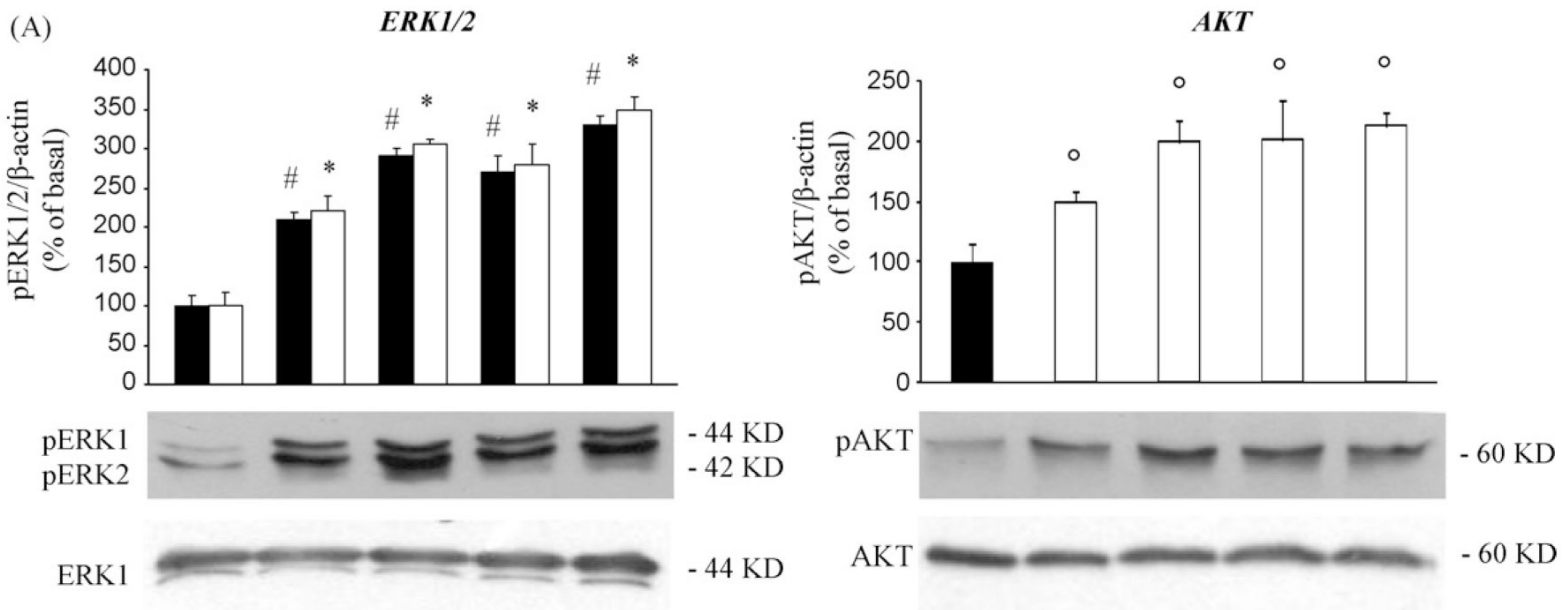

$\beta$-actin



aERK1 $\square$ pERK2

(B)

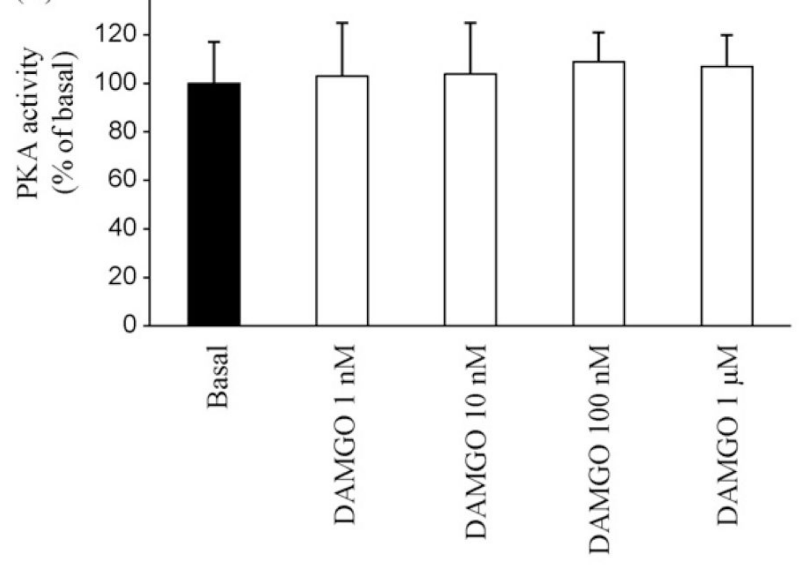

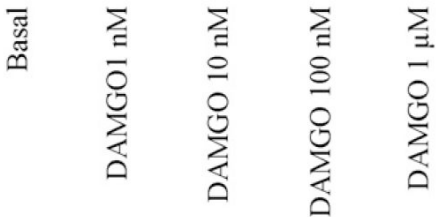

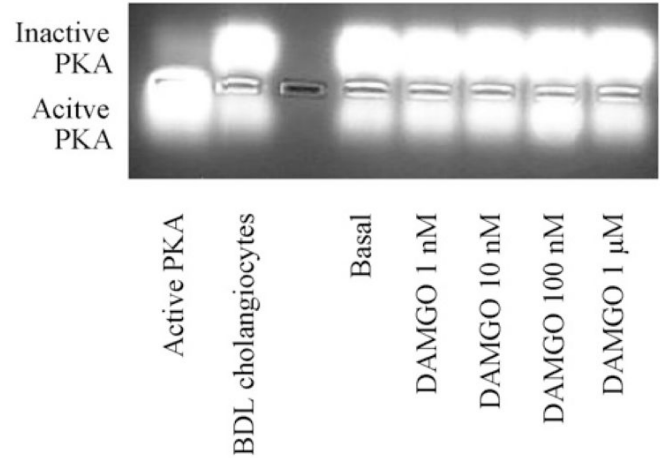


(C)
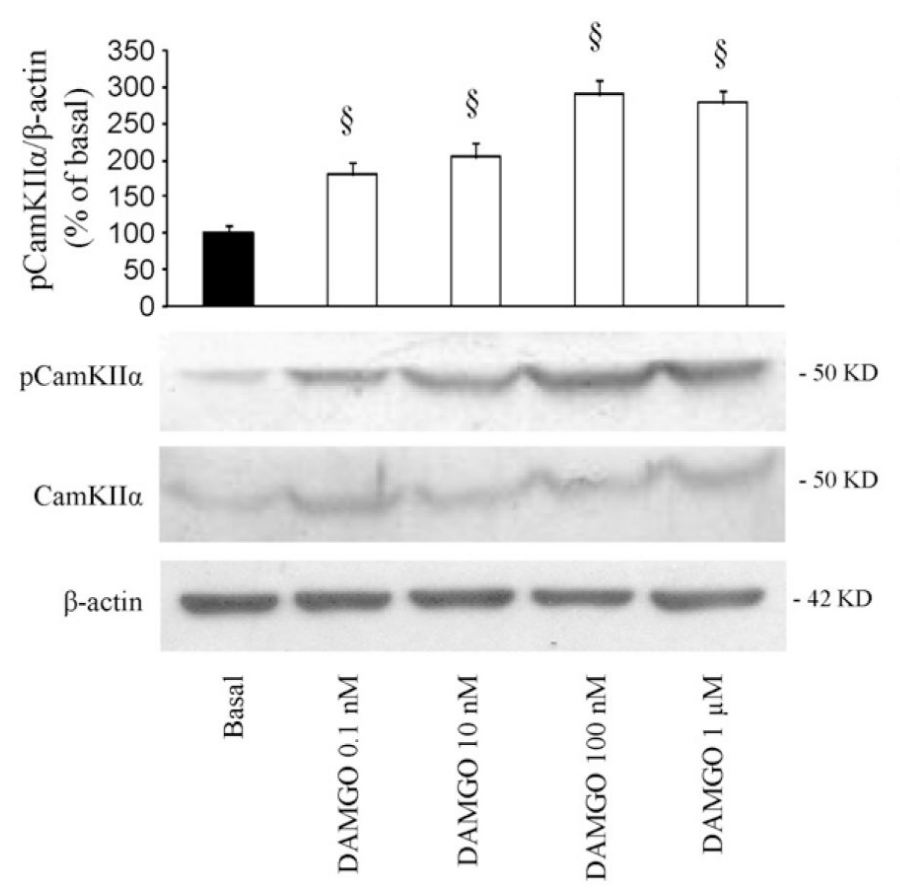

PKCa
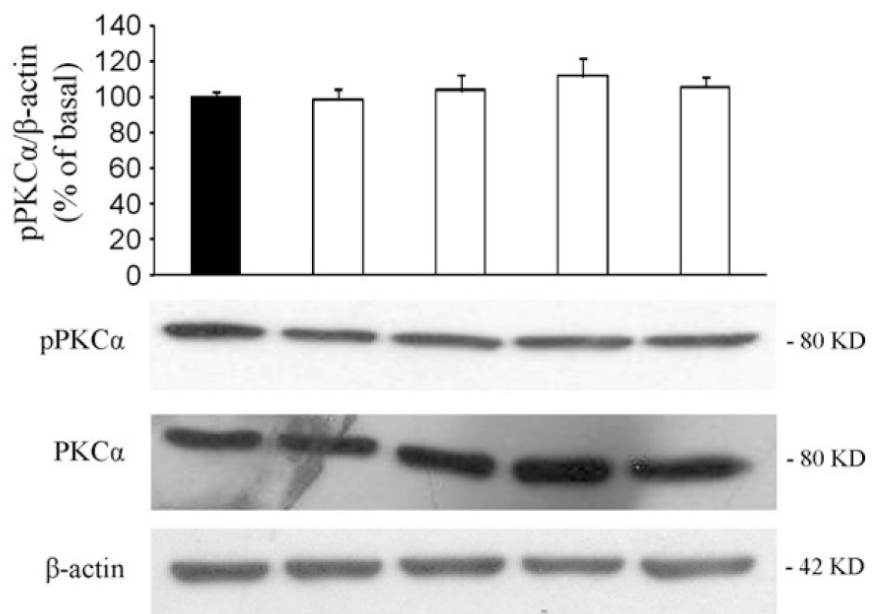

Fig. 3.

Effect of $\mu \mathrm{OR}$ activation on intracellular signalling in $\mathrm{HuH}-28$ cells. (A) Incubation with increasing doses of DAMGO corresponded to a dose-dependent increase of ERK1/2 (left) and AKT (right) phosphorylation. Data are expressed as mean \pm S.E. of three experiments. ${ }^{\#} p<$ 0.05 vs. pERK 1 basal value; ${ }^{*} p<0.05$ vs. pERK2 basal value; ${ }^{\circ} p<0.05$ vs. pAKT basal value. (B) Incubation with increasing doses of DAMGO did not induce significant changes in PKA activity (left); active PKA provided by the vendor and cholangiocytes isolated from rats subjected to 1 week BDL were taken as positive controls (right, representative image). Data are expressed as mean \pm S.E. of three experiments. (C) $\mu \mathrm{OR}$ activation corresponded to a dosedependent increase of CamKII $\alpha$ (left) but not PKC $\alpha$ (right) phosphorylation. Data are expressed as mean \pm S.E. of three experiments. ${ }^{\S} p<0.05$ vs. pCamKII $\alpha$ basal value. 


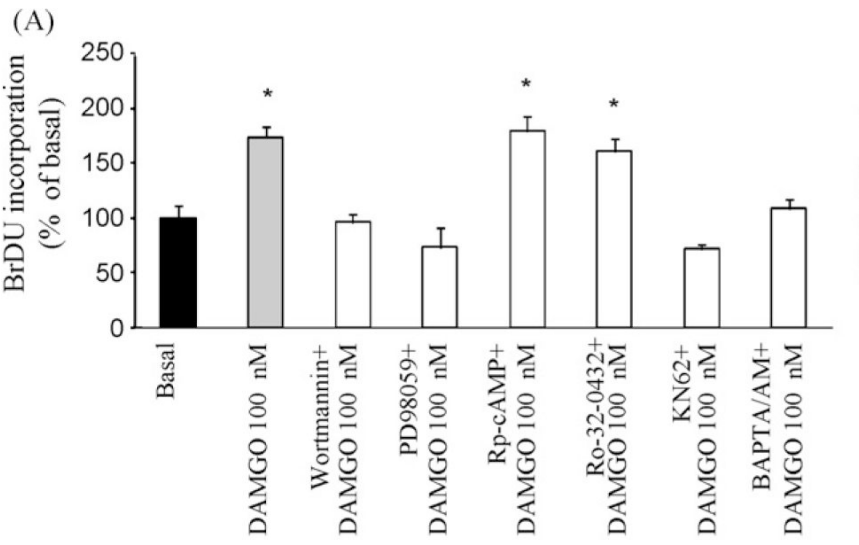

(B)
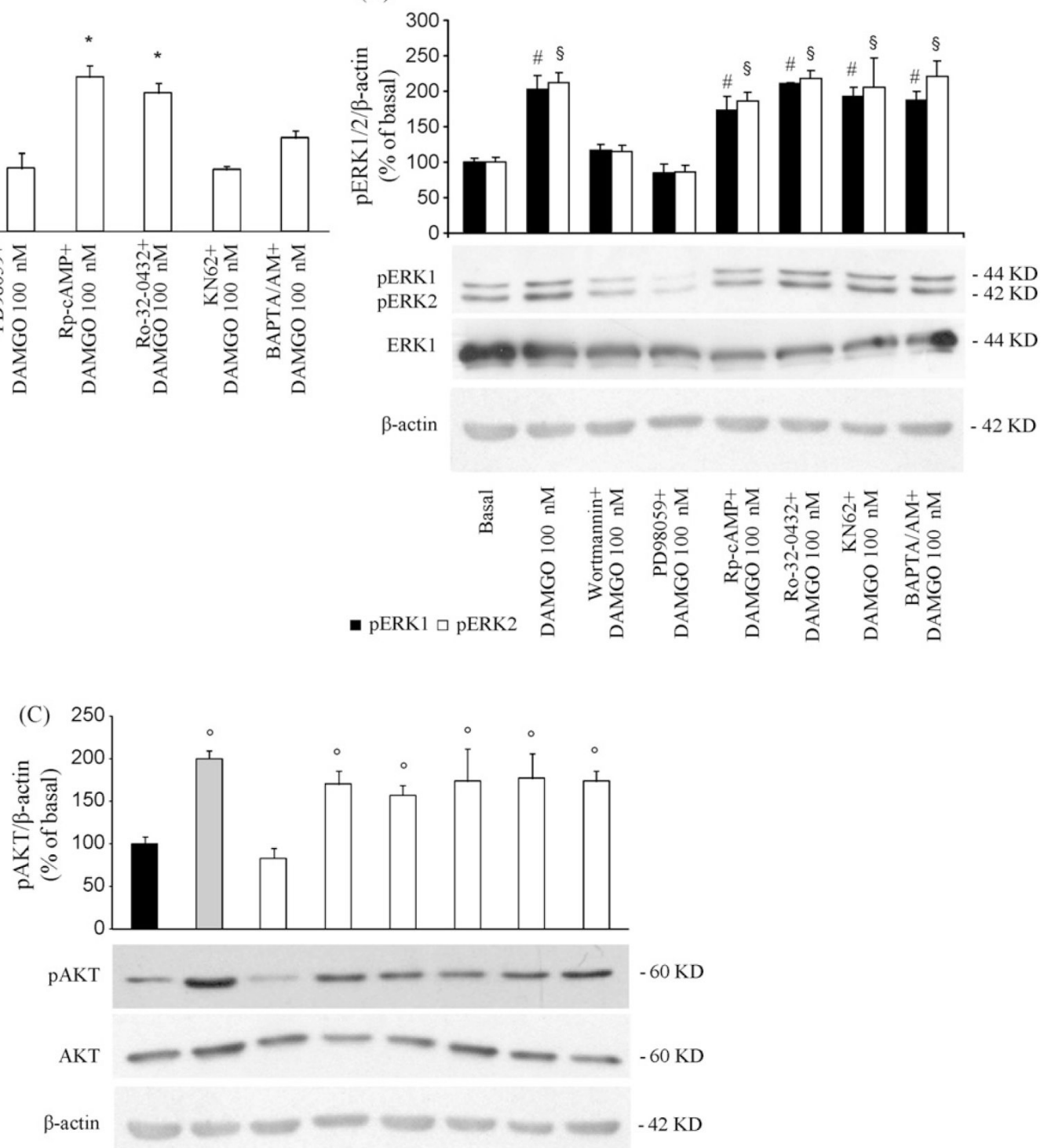

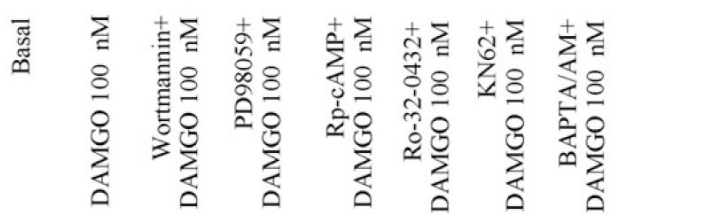

Fig. 4.

(A) The DAMGO-induced increase in HuH-28 cell proliferation was neutralised by the preincubation with PI3K (wortmannin), MEK (PD98059) and CamKII (KN62) inhibitors and with the intracellular $\mathrm{Ca}^{2+}$ chelator (BAPTA/AM). In contrast, DAMGO-induced increase in cell proliferation was not affected by the pre-incubation with the cAMP-dependent PKA inhibitor (Rp-cAMPs) or the $\mathrm{Ca}^{2+}$-dependent PKC inhibitor (Ro-32-0432). Data are expressed as mean \pm S.E. of three experiments. ${ }^{*} p<0.05$ vs. the other groups. (B) Only PI3K and MEK inhibitors blocked the DAMGO-induced increase in ERK1/2 phosphorylation, whereas no effect was observed after the pre-incubation with the other inhibitors. Data are expressed as mean \pm S.E. of three experiments. ${ }^{\#} p<0.05$ vs. pERK1 value of the other groups; ${ }^{{ }} p<0.05$ vs. pERK2 
value of the other groups. (C) DAMGO-induced increase in AKT phosphorylation was neutralised only by the PI3K inhibitor wortmannin. Data are expressed as mean \pm S.E. of three experiments. ${ }^{\circ} p<0.05$ vs. the other groups. 

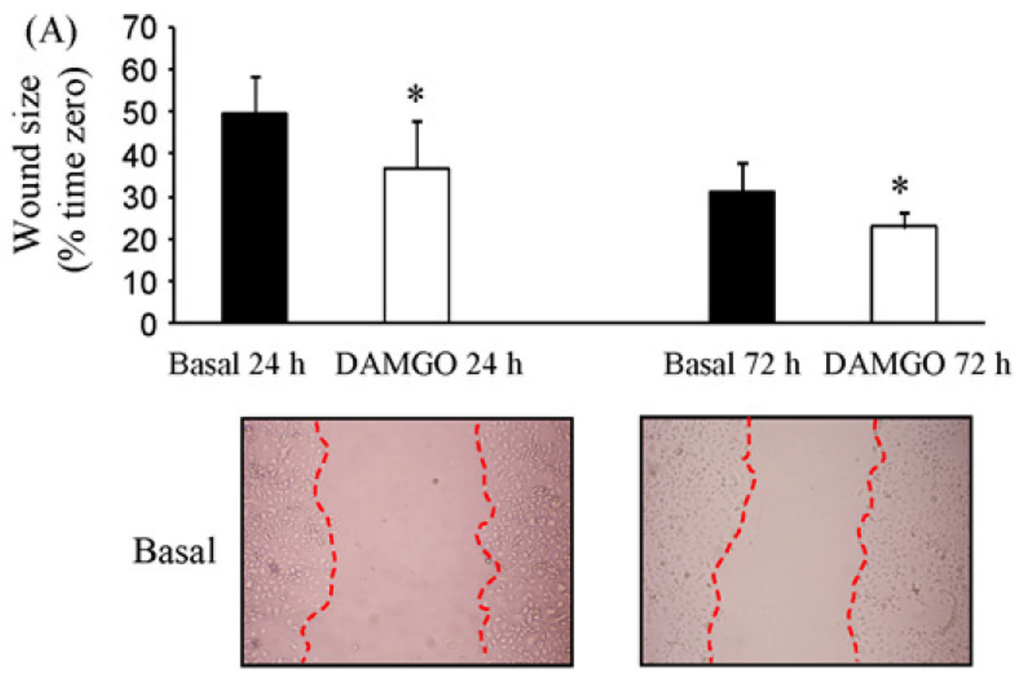

DAMGO $100 \mathrm{nM}$

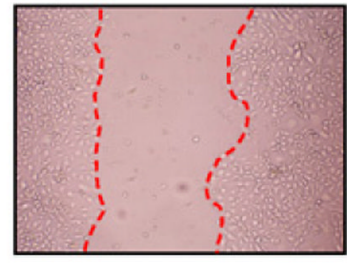

$24 \mathrm{~h}$

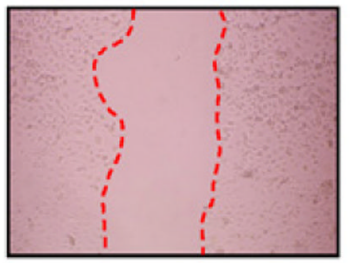

$72 \mathrm{~h}$

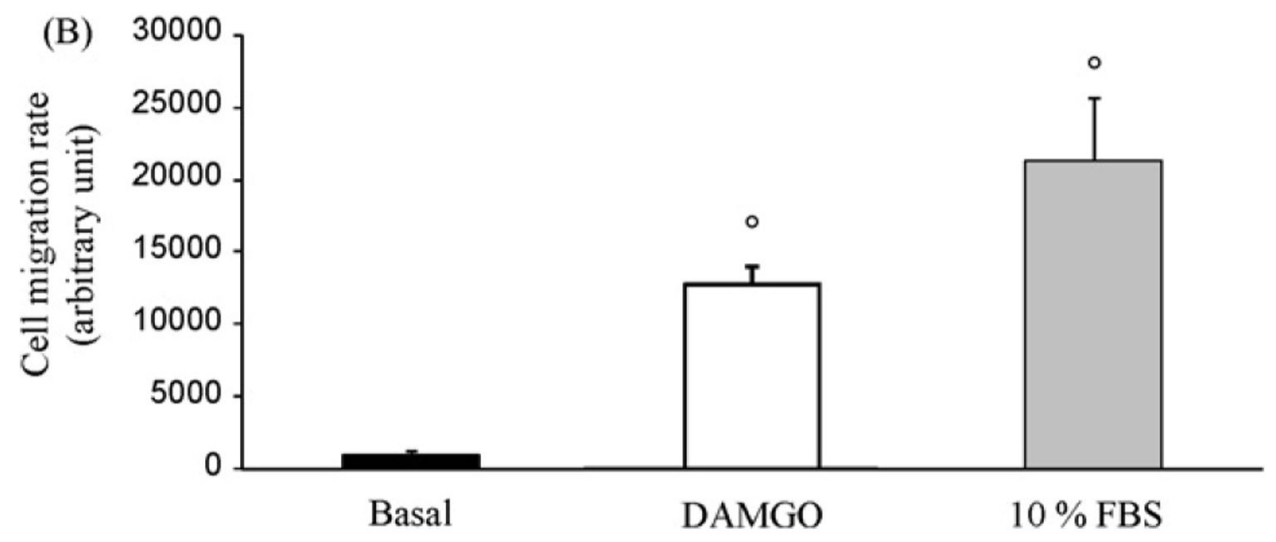

Fig. 5.

Effect of $\mu \mathrm{OR}$ activation on HuH-28 cell migration and survival. (A) Wound-healing experiments showed that $\mu \mathrm{OR}$ activation markedly diminished both after 24 and $72 \mathrm{~h}$, the area included within the wound margins (outlined by the red-scattered line). Data are expressed as mean \pm S.E. of three experiments. ${ }^{*} p<0.05$ vs. the corresponding basal value. (B) Cell migration assay demonstrated that the $\mu$ OR selective agonist DAMGO markedly enhanced HuH-28 cell migration; cells cultured in 10\% FBS enriched medium were used as positive control. Data are expressed as mean \pm S.E. of three experiments. ${ }^{\circ} p<0.05$ vs. basal. 



Fig. 6.

(A) Incubation of HuH-28 cells with GCDCA resulted in marked activation of caspase 3; such effect was reduced when cells were pre-incubated with DAMGO. Data are expressed as mean \pm S.E. of three experiments. ${ }^{\#} p<0.05$ vs. basal; ${ }^{\S} p<0.05$ vs. GCDCA+DAMGO. (B) Only the pre-incubation with wortmannin neutralised the effects of DAMGO on GCDCA-induced increase in caspase 3 activity assay. No effects were seen when cells were pre-incubated with PD98059 or KN62. Data are expressed as mean \pm S.E. of three experiments. $* p<0.05$ vs. the other groups. 